\title{
Editorial
}

\section{Ischaemic heart failure: is prevention in sight?}

Heart failure is a common clinical syndrome with a poor prognosis. It has been estimated that about 2 million patients in the United States have clinical congestive heart failure, and the incidence is increasing. ${ }^{1}$ In the United Kingdom the estimated prevalence of heart failure is 3.9 per 1000 patients. $^{2}$ The prognosis seems to be similar world wide.

Although heart failure can be caused by various pathological processes, the single most frequent cause is left ventricular systolic dysfunction-resulting from myocardial ischaemic injury caused by atherosclerotic obstructive coronary artery disease.

\section{Acute ischaemic heart failure}

The extent of myocardial injury is the major determinant of the severity of heart failure and of the immediate and late prognosis. For example, in patients with acute myocardial infarction, ischaemic injury of $30-40 \%$ of the left ventricular myocardium produces severe left ventricular failure often with clinical cardiogenic shock. The immediate mortality of such patients exceeds $80 \%$ despite aggressive pharmacological and non-pharmacological supportive therapy. ${ }^{3}$ Even those who survive the acute episode of heart failure soon die of progressive chronic heart failure. ${ }^{4}$ Thus the importance of limiting infarct size in the prevention of acute severe heart failure cannot be over emphasised. Of all the therapeutic interventions that have been attempted to limit the extent of myocardial injury, early recanalisation of the infarct related artery and re-establishment of flow to the ischaemic myocardium by using thrombolytic agents have shown the greatest promise. Clinical experience suggests that the incidence of severe, acute post-infarction heart failure declined after the introduction of thrombolytic therapy. It appears, however, that intravenous thrombolytic therapy does not influence the high mortality of patients with cardiogenic shock caused by severe left ventricular failure. $^{5}$ Uncontrolled studies have reported improved immediate and short-term (about three months) late prognosis in these patients after successful angioplasty or revascularisation surgery performed within 24 hours of the onset of infarction. ${ }^{67}$ The mechanism for this apparent improvement in prognosis is presumably better perfusion and the larger extent of salvage of ischaemic myocardium. Nevertheless, the residual myocardial injury and the magnitude of left ventricular dysfunction are considerable even after successful reperfusion therapy and overt heart failure is likely to develop in time. It is apparent that, in addition to presently available strategies of reperfusion therapy, further progress in therapeutic interventions to limit the extent of myocadial injury will be necessary to reduce the incidence of acute severe left ventricular failure, which carries such a poor prognosis.

\section{Chronic ischaemic heart failure}

Chronic heart failure, which also carries a poor prognosis, is a frequent sequel to myocardial infarction. In patients with documented previous myocardial infarction, the risk of the development of symptomatic heart failure may be 7-10 times higher than that in a matched normal population. ${ }^{8}$ In the SAVE trial $16 \%$ of the placebo treated patients developed heart failure during the follow up period of 42 months. ${ }^{9}$

\section{Overt heart failure}

Once overt heart failure develops the prognosis worsens and mortality increases with increasing severity of heart failure. Several uncontrolled studies have reported that the one year mortality in patients with severe heart failure (New York Heart Association (NYHA) class IV) may exceed $50 \% .^{10}$ In the CONSENSUS I prospective trial, 6 month and 12 month mortality calculated from the cumulative time-mortality curve of patients with NYHA class IV heart failure, treated conventionally, was 48 and $63 \%$ respectively. ${ }^{11}$ Mortality was higher in patients who were clinically unstable or who required admission to hospital for treatment of pulmonary oedema and low output state. ${ }^{12}$ Considerable activation of the adrenergic and renin-angiotensin systems; increased concentrations of atrial natriuretic peptide, aldosterone, and vasopressin; and hyponatraemia have been reported to be risk factors. ${ }^{13} 14$ It is not entirely clear whether these neuroendocrine and electrolyte abnormalities are markers of severe heart failure or whether these changes contribute to progression of heart failure by their primary and secondary effects on peripheral circulation and myocardial function. Increased left ventricular ejection impedance caused by peripheral vasoconstriction can cause worsening heart failure because of further impairment of cardiac performance. ${ }^{15}$ Angiotensin II and noradrenaline may also produce myocardial dysfunction by inducing myocardial hypertrophy, myocyte loss, and extracellular architectural changes which may also contribute to progression of heart failure. ${ }^{16}$ If this hypothesis is correctthat is, the activated renin, angiotensin, and adrenergic systems participate in the progression of heart failure-it may be possible to counter their adverse effects pharmacologically and prevent progressive heart failure. Intervention with angiotensin converting-enzyme inhibitors undeniably improved the outcome of patients with severe ischaemic heart failure in prospective randomised trials. For example, in the CONSENSUS I trial, in which most patients had coronary artery disease, there was a $40 \%$ and $31 \%$ reduction in the relative risk of mortality at 6 and 12 months respectively when enalapril was added to conventional treatment. ${ }^{11}$ Even in the group treated with enalapril, however, the mortality at 6 months 
was $26 \%$ and that at 12 months was $36 \%$-a much higher mortality than that seen in many malignant conditions. Though there was a considerable improvement in symptoms and clinical class of heart failure with enalapril treatment, many patients died of progressive heart failure. These findings suggest that once severe heart failure develops angiotensin converting enzyme inhibitors are only partially effective in preventing further progression of heart failure and in improving prognosis. The prospect of improving prognosis of these patients with refractory heart failure with addition of newer vasodilators or inotropic agents does not seem promising. In the PROMISE trial there was an increase in mortality with the addition of milrinone, a vasodilator and a phosphodiesterase inhibitor. ${ }^{17}$

It has been postulated that an earlier intervention may prevent the development of severe heart failure and improve the prognosis of patients with mild to moderate heart failure. In the Veterans Administration Heart Failure trial I (V-HeFT I), with hydralazine/isosorbide dinitrate and in V-HeFT II, with hydralazine, isosorbide dinitrate, or enalapril, the mortality risk decreased significantly. ${ }^{18}{ }^{19}$ In the SOLVD treatment trial there was a $16 \%$ decrease in mortality in patients on active therapy. ${ }^{12}$

As well as a decrease in mortality, there was a substantial reduction in the proportion of patients who required admission to hospital for the further management of heart failure. Therefore, it seems that in patients with mild to moderate heart failure, earlier use of angiotensin converting-enzyme inhibitors not only improves the overall prognosis, but also may delay the development of more severe heart failure. Once clinical heart failure is severe enough to require admission to hospital, however, mortality remains high. Thus the prevention of the development of clinical heart failure after myocardial injury has emerged as a very important therapeutic concept.

\section{Asymptomatic left ventricular dysfunction}

Prospective randomised clinical trials have shown that pharmacological interventions can delay the development of heart failure and improve prognosis of patients with asymptomatic left ventricular systolic dysfunction caused by ischaemic heart disease. In the SOLVD prevention trial, treatment with enalapril reduced the risk of development of heart failure by $29 \%$, delayed it by an average of 24 months, and reduced the combined incidence of heart failure and death. Approximately $80 \%$ of patients randomised in this study had ischaemic heart disease and prior myocardial infarction. In the SAVE trial, treatment with captopril was associated with decreases in all cause mortality risk $(19 \%)$, in the risk of death from cardiovascular causes $(21 \%)$, in the risk of development of severe heart failure $(22 \%)$, and in the need for hospital admission for treatment of congestive heart failure (22\%). These results provide incontrovertible evidence of the potential for the prevention of heart failure and hence for the improvement of prognosis by early intervention with angiotensin converting enzyme inhibitors in symptom free patients with "ischaemic" left ventricular systolic dysfunction.

The mechanisms for these beneficial effects of angiotensin converting enzyme inhibitors have not been clearly elucidated. Both in the SAVE and SOLVD trials, the risk of recurrent myocardial infarction decreased significantly during treatment with angiotensin converting enzyme inhibitors. ${ }^{912}$ Angiotensin converting enzyme inhibitors have been shown to improve coronary haemodynamics and myocardial energetics in patients with chronic ischaemic heart failure. ${ }^{21} 22$ Thus their anti- ischaemic effects may play a part in the prevention of the progression of heart failure.

\section{Prevention of ischaemic heart failure}

After myocardial injury, progressive ventricular enlargement, and architectural and geometric changes (remodelling) often occur when the extent of myocardial injury exceeds certain limits. ${ }^{23-25}$ Ventricular enlargement and impaired left ventricular systolic function are established major risk factors for early and late mortality in patients with myocardial infarction. ${ }^{26-28}$ It is also highly probable that "remodelling" and decreased left ventricular ejection fraction are the principal antecedent mechanisms for the development of chronic ischaemic heart failure. Angiotensin converting enzyme inhibitors have been reported to retard progressive ventricular enlargement and decrease ventricular mass. ${ }^{29-33}$

Attenuation of ventricular remodelling may be due to the favourable effects of angiotensin converting enzyme inhibitors on ventricular loads and/or the reduction of myocytolysis and myocardial architectural changes mediated by angiotensin II. ${ }^{34}$ Whatever the mechanisms may be, angiotensin converting enzyme inhibitors can delay the development of heart failure and should be considered in the management of symptom free patients with impaired left ventricular systolic function.

Though glyceryl trinitrate administered during the acute phase of myocardial infarction has been reported to reduce ventricular enlargement, its role in the prevention of heart failure has not been firmly established..$^{35}$

\section{Reduction of the extent of ischaemic injury}

The beneficial effects of angiotensin converting enzyme inhibitors are seen only when left ventricular systolic function after injury is initially impaired. In experimental myocardial infarction in animals, left ventricular dilatation with an increase in wall stress usually does not occur when the infarcts are small..$^{29}{ }^{36}$ In the SOLVD treatment trial enalapril did not reduce mortality in patients with left ventricular ejection fractions of between $30 \%$ and $35 \% .{ }^{12}$ The benefits in terms of the effect on the combined endpoint of death or hospital admission were also minimal in this group of patients. Similarly, in the SOLVD prevention trial there was a significant trend towards less benefit from enalapril among patients with a higher ejection fraction..$^{20}$ In the SAVE trial, however, the beneficial effect of captopril therapy on cardiovascular morbidity and death were similar when initial ejection fraction was between $32 \%$ and $40 \%$ or when it was less than $32 \% .^{9}$ But the likelihood of a reduction in all cause mortality seems to be less in patients with a higher initial ejection fraction.

The risk of development of heart failure in ischaemic heart disease is much less and the prognosis is much better when left ventricular systolic function is preserved than when it is impaired. Thus preservation of left ventricular systolic function should be considered as one of the major therapeutic goals for prevention of "ischaemic" heart failure. Many recent studies have found that the residual left ventricular global ejection fraction frequently exceeds $50 \%$ in patients with acute myocardial infarction receiving very early reperfusion therapy. ${ }^{37}$ Furthermore, an open infarct related artery is associated with reduced infarct expansion and ventricular enlargement. ${ }^{38}$

Thus the available information indicates that prevention of ischaemic heart failure is indeed a practical proposition. Early reperfusion of the ischaemic myocardium to 
decrease the extent of myocardial injury and to preserve left ventricular systolic function should be considered as an important part of the overall therapeutic strategy for prevention of ischaemic heart failure. Patients with impaired left ventricular systolic function despite successful reperfusion therapy should receive angiotensin converting-enzyme inhibitors routinely until better treatments become available to prevent ischaemic heart failure.

KANU CHATTERJEE PETER COLLINS

Department of Cardiac Medicine,

National Heart and Lung Institute,

Dovehouse Street,

London SW3 $6 L Y$

1 Yusuf S, Thom T, Abbott RD. Changes in hypertension treatment and in congestive heart failure mortality in the United States. Hypertension congestive heart

2 Parameshwar J, Shackell MM, Richardson A, Poole-Wilson PA, Sutton GC. Prevalence of heart failure in three general practices in north west London. Br $\mathcal{F}$ Gen Pract 1992;42:287-9.

3 Alonso DR, Scheidt S, Post M, Killip T. Pathophysiology of cardiogenic shock. Quantification of myocardial necrosis, clinical, pathologic and electrocardiographic correlations. Circulation 1973;48:588-96.

4 Chatterjee K, Swan HJ, Kaushik VS, Jobin G, Magnusson P, Forrester JS. Effects of vasodilator therapy for severe pump failure in acute myocardial infarction on short-term and late prognosis. Circulation 1976;53:797-802.

5 Gruppo Italiano per lo Studio della Streptochinasi Nell'Infarto Miocardico (GISSI). Effectiveness of intravenous thrombolytic treatment in acute myocardial infarction. Lancet 1986;i:397-402.

6 Lee L, Erbel R, Brown TM, Laufer N, Meyer J, O'Neill WW. Multicenter registry of angioplasty therapy of cardiogenic shock: initial and long-term survival. $\mathcal{F} \mathrm{Am}$ Coll Cardiol 1991;17:599-603.

7 Moosvi AR, Khaja F, Villanueva L, Gheorghiade M, Douthat L, Goldstein S. Early revascularization improves survival in cardiogenic shock complicating acute myocardial infarction. $\mathcal{F} \mathrm{Am}$ Coll Cardiol 1992;19:907-14

8 Kannel WB. Epidemiology and prevention of cardiac failure: Framingham Study insights. Eur Heart 7 1987;8(Suppl F):23-6.

9 Pfeffer MA, Braunwald E, Moyé LA, et al. Effect of captopril on mortality and morbidity in patients with left ventricular dysfunction after myocardial infarction. Results of the survival and ventricular enlargement trial. N Engl $¥$ Med 1992;327:669-77.

10 Massie B, Ports $\mathrm{T}$, Chatterjee $\mathrm{K}$, et al. Long-term vasodilator therapy for heart failure: clinical response and its relationship to hemodynamic heart failure: clinical response and its re

11 The CONSENSUS Trial Study Group. Effects of enalapril on mortality in severe congestive heart failure. Results of the Cooperative North Scandinavian Enalapril Survival Study (CONSENSUS). $N$ Engl $\mathfrak{f}$ Med 1987;316:1429-35.

12 The SOLVD Investigators. Effect of enalapril on survival in patients with reduced left ventricular ejection fractions and congestive heart failure. $N$ Engl f Med 1991;325:293-302.

13 Swedberg K, Eneroth P, Kjekshus J, Wilhelmsen L. Hormones regulating cardiovascular function in patients with severe congestive heart failure and their relation to mortality. CONSENSUS Trial Study Group. Circulation 1990;82:1730-6.

14 Packer M. The neurohormonal hypothesis: a theory to explain the mechanism of disease progression in heart failure. $\mathcal{F} \mathrm{Am}$ Coll Cardiol 1992;20:248-54.

15 Chatteriee K, Parmley WW. The role of vasodilator therapy in heart failure. Prog Cardiovasc Dis 1977;19:301-25.
16 Michel JB, Lattion AL, Salzmann JL, et al. Hormonal and cardiac effects of converting enzyme inhibition in rat myocardial infarction. Circ Res 1988;62:641-50.

17 Packer M, Carver JR, Rodeheffer RJ, et al. Effect of oral milrinone on mortality in severe chronic heart failure. The PROMISE Study Research Group. N Engl ₹ Med 1991;325:1468-75.

18 Cohn JN, Archibald DG, Ziesche S, et al. Effect of vasodilator therapy on mortality in chronic congestive heart failure. Results of a Veteran mortality in chronic congestive heart failure. Results of a Vetera

19 Cohn JN, Johnson G, Ziesche S, et al. A comparison of enalapril with hydralazine-isosorbide dinitrate in the treatment of chronic congestive heart failure. $N$ Engl f Med 1991;325:303-10

20 The SOLVD Investigators. Effect of enalapril on mortality and the development of heart failure in asymptomatic patients with reduced left ventricular ejection fractions. N Engl $₹$ Med 1992;327:685-91

21 Rouleau JL, Chatterjee K, Benge W, Parmley WW, Hiramatsu B Alterations in left ventricular function and coronary hemodynamics with captopril, hydralazine and prazosin in chronic ischemic heart failure: comparative study. Circulation 1982;65:671-8.

22 De Marco T, Daly PA, Liu M, Kayser S, Parmley WW, Chatterjee K Enalaprilat, a new parenteral angiotensin-converting enzyme inhibitor: rapid changes in systemic and coronary hemodynamics and humoral profile in chronic heart failure. $₹ \mathrm{Am}$ Coll Cardiol 1987;9:1131-8.

23 Weisman HF, Healy B. Myocardial infarct expansion, infarct extension, and reinfarction: pathophysiologic concepts. Prog Cardiovasc Dis 1987:30:73-110.

24 Vannan MA, Taylor DJE. Ventricular remodelling after myocardial infarction. Br Heart $\mathcal{f}$ 1992;68:257-9.

25 The Multicenter Postinfarction Research Group. Risk stratification and survival after myocardial infarction. $N$ Engl f Med 1983;309:331-6.

26 Hammermeister KE, DeRouen TA, Dodge HT. Variables predictive of survival in patients with coronary disease. Selection by univariate and multivariate analyses from the clinical, electrocardiographic, exercise, arteriographic, and quantitative angiographic evaluations. Circulation 1979;59:421-30.

27 McKay RG, Pfeffer MA, Pasternak RC, et al. Left ventricular remodeling after myocardial infarction: a corollary to infarct expansion. Circulation 1986;74:693-702.

28 White HD, Norris RM, Brown MA, Brandt PW, Whitlock RM, Wild CJ. Left ventricular end-systolic volume as the major determinant of survival after recovery from myocardial infarction. Circulatio 1987;76:44-51.

29 Pfeffer JM, Pfeffer MA, Braunwald E. Influence of chronic captopril therapy on the infarcted left ventricle of the rat. Cir Res 1985;57:84-95.

30 Sharpe N, Murphy J, Smith H, Hannan S. Treatment of patients with symptomless left ventricular dysfuction after myocardial infarction. Lancet 1988;i:255-9.

31 Pfeffer MA, Lamas GA, Vaughan DE, Parisi AF, Braunwald E. Effect of captopril on progressive ventricular dilatation after anterior myocardial infarction. $N$ Engl f Med 1988;319:80-6.

32 Doherty NE, Seelos KC, Suzuki J, et al. Application of cine nuclear magnetic resonance imaging for sequential evaluation of response to angiotensin-converting enzyme inhibitor therapy in dilated cardiomyangiotensin-converting enzyme inhibitor the

33 Jugdutt BI, Schwarz-Michorowski BL, Khan MI. Effect of long-term captopril therapy on left ventricular remodeling and function during healing of canine myocardial infarction. F Am Coll Cardiol 1992;19:713-21.

34 Tan LB, Jalil JE, Pick R, Janicki JS, Weber KT. Cardiac myocyte necrosi induced by angiotensin II. Circ Res 1991;69:1 185-95.

35 Jugdutt BI, Warnica JW. Intravenous nitroglycerin therapy to limit myocardial infarct size, expansion, and complications. Effect of timing, dosage, and infarct locations. Circulation 1988;78:906-19.

36 Pfeffer MA, Braunwald E. Ventricular remodeling after myocardial infarction. Experimental observations and clinical implications. Circulation 1990;81:1161-72.

37 O'Rourke M, Baron D, Keogh A, et al. Limitation of myocardial infarction by early infusion of recombinant tissue-type plasminogen activator tion by early infusion of recom

38 Siu SC, Nidorf SM, Galambos GS, Weyman AE, Picard MH. The effect of late patency of the infarct-related coronary artery on left ventricular
morphology and regional function after thrombolysis. Am Heart $\mathcal{f}$ 1992;124:265-72. 